\title{
A MONTAGEM EM \\ ELES ERAM MUITOS CAVALOS, DE LUIZ RUFFATO: CONVERSAÇÕES ENTRE CINEMA E LITERATURA
}

\author{
João Guilherme Dayrell \\ Mestrando em Teoria da Literatura - UFSC
}

\begin{abstract}
RESUMO
$\mathrm{O}$ trabalho visa estabelecer relações entre a fragmentada narrativa presente em eles eram muitos cavalos, de Luiz Ruffato, e a montagem cinematográfica. Operando pelo corte e repetição, condições, segundo Agamben, possibilitadoras da montagem, a referida obra de Ruffato nos coloca em um passeio por 70 fragmentos: o último precedido por duas páginas negras. Verificase aqui a afinidade com as vanguardas cinematográficas do pós-guerra onde predomina imagens-tempo (Deleuze), que exibem sua medialidade: não há mais um significado ulterior resultante do embate dos enunciados. Assim, eles eram muitos cavalos desconstrói a realidade e traz a repetição não como retorno ao idêntico, mas como possibilidade daquilo que foi: meio sem fim.
\end{abstract}

PALAVRAS-CHAVE

Eles eram muitos cavalos; Montagem; Meio sem fim.

\section{THE MONTAGE IN ELES ERAM MUITOS CAVALOS, BY LUIZ RUFFATO: CONVERSATIONS BETWEEN FILM AND LITERATURE}

\begin{abstract}
The paper aims at establishing connections between the fragmented narrative eles eram muitos cavalos, by Luiz Ruffato, and montage. Through cut and repetition, which, according to Agamben, may be necessary conditions to enable montage, the referred work by Ruffato places us on a tour of seventy fragments: the latter preceded by two black pages. Here it is possible to identify the affinity with the avant-garde cinema of the post-war, where there is the predominance of time-images (Deleuze), which reveal their mediality: there is no longer an ulterior significance resulting from the collision of the statements. So eles eram muitos cavalos deconstructs reality and promotes repetition not as a return to the same, but as a possibility of what has been: means without end.
\end{abstract}

\section{KEYWORDS}

Eles eram muitos cavalos; Montage; Means without end. 


\section{INTRODUÇÃO}

"O cinema procurava uma coisa, a montagem, e é dessa coisa que o homem do século XX tinha muita necessidade" (GODARD APUD AGAMBEN, 2000. p 3)

Uma leitura/literatura feita de cortes: os olhos saltam de um flagrante do submundo onde crianças dormem ao lado de imundos ratos em um lugar qualquer da cidade de São Paulo diretamente para um quadro de horóscopo ou lista de livros bestsellers que se encontra facilmente em qualquer jornal diário; da vida de uma meretriz e seu depoimento abafado pela voz do narrador que assume o corpo da narrativa sem grandes pudores, intercalando assim, seu silencioso desabafo sobre as atrocidades que sofre no mundo da prostituição para o insólito bate-papo pela internet, recheado dos vulgares maneirismos característicos de tais conversas. Da descrição do absurdo e das situações inumanas que povoam o cotidiano da metrópole contemporânea direto para as cenas mais corriqueiras e vazias do dia a dia.

Uma literatura/leitura feita de repetições: um texto explicitamente decomposto, recheado de citações; a descrição da vida perpassada pelos simulacros ${ }^{1}$, onde as setenta passagens - todas numeradas até a penúltima, onde se vê um cardápio de restaurante que é interrompido por duas páginas negras que antecedem último relato, para o qual não se imputa numeração - possuem importância por si mesmas numa relação de independência umas com as outros. Rizoma ${ }^{2}$ : conexões com vetores infinitos a serem feitas pelos elementos desta rede destituída de hierarquia, deste emaranhado, por aquele que pretende juntar estas ruínas, como diz Compagnon a partir de uma citação de Quintiliano:

'A leitura é livre e não é obrigada a acompanhar o orador. Pode-se
voltar a cada instante sobre os próprios passos, seja para examinar
uma passagem mais atentamente, seja para melhor memorizá-la'.
Voltar sobre os próprios passos, memorizar (repetere, para

\footnotetext{
${ }^{1}$ BAUDRILLARD, Jean. Simulacra and Simulation. Translated by Sheila Faria Glaser. The University of Michigan, 1994. P. 30 O autor diz: O meio não é mais identificado como tal, e a Simulaçao que confunde meio e mensagem (McLuhan) é a melhor fórmula desta nova era. Não há mais um meio no sentido literal: agora ele se torna intangível, difuso e difratado no real, e ninguém mais pode dizer que o meio é alterado por isso. Trad. livre.

2 DELEUZE, Gilles. Mil Platôs. Capitalismo e Esquizofrenia V. 1. Tradução Ana Lúcia de Oliveira. São Paulo: Editora 34. $5^{\circ}$ reimpressão. 2007
} 
Quintiliano) é decompor o texto, alterar sua organização. (COMPAGNON, 2007, p. 14)

Eis eles eram muitos cavalos, de Luiz Ruffato (2001), cuja estrutura força o processo verificado como inerente a leitura de qualquer obra - presunção esta em decorrência da abordagem teórica realizada por Compagnon (2007) na citação acima feita sem eleger nenhum texto específico - e que aqui terá sua potencialidade extremamente elevada. Um texto destituído de linearidade que desmonta a vida na metrópole contemporânea induzindo uma leitura atenta à captação dos flashes transmitidos por esta câmera operada pela repetição e pelo corte. E o que são estas duas características? O que nos coloca a repetição ao lado do corte? Combinados, estes dois procedimentos são as condições principais de um artifício ao qual nos dedicaremos toda a análise: a montagem. Giorgio Agamben diz que:

Em filosofia, desde Kant chamamos condições de possibilidade de alguma coisa os transcendentais. Quais são os transcendentais da montagem? Há duas condições transcendentais da montagem, a repetição e o corte. (AGAMBEN, 2007, p. 3)

Em um breve artigo publicado na revista Aletria, de Belo Horizonte, Susanna Busato Feitosa (2001) nos leva às relações tão perceptíveis entre Oswald de Andrade e Sergei Eisenstein. Oswald, no livro Memórias Sentimentais de João Miramar (1924) ${ }^{3}$, por exemplo, propõe uma narrativa em pequenos fragmentos, que à semelhança do objeto que nos servirá para análise no presente artigo os numera durante parte da narrativa. Mas há diferenças entre as duas obras, entre a montagem que propõe o cineasta e teórico russo do cinema Sergei Eisenstein $(1929)^{4}$ cujo diálogo está para Oswald e na auto-suficiência que é perceptível nas pequenas passagens de Luiz Ruffato. É justamente essa passagem, essa transformação que nos interessa, pois há aqui outro estatuto desta montagem: trata-se de uma relação com outros cinemas, trata-se de outra literatura. Se de um lado está o processo metonímico que deixa as pequenas partes submetidas a um todo, onde a importância de cada fragmento é menos que a relação entre os fragmentos; há na outra mão a montagem que se faz através da valorização do

\footnotetext{
${ }^{3}$ Data da primeira publicação da obra pela editora Independência. Tivemos acesso à edição que consta na bibliografia.

${ }^{4} \mathrm{O}$ mesmo em relação à data de publicação do trabalho e à edição que tivemos acesso segue com o diretor russo.
} 
momento em detrimento de sua possível estrutura de causa e efeito em relação aos demais, que se debruça sobre a interrupção não se propondo a ilustrar as situações ou favorecer seus desenvolvimentos: é puramente gestual. ${ }^{5}$ É justamente a última descrição que nos coloca com maior pertinência ao se lançar os olhos sobre eles eram muitos cavalos, de Luiz Ruffato (2001).

Mas é também da constatação acima feita previamente sem uma análise de fato que reside a importância de voltarmos um pouco e contextualizar melhor o panorama teórico ao qual iremos nos ater. Tal movimento é necessário, pois as relações que serão estabelecidas entre cinema e literatura aqui, obviamente não dizem respeito a qualquer cinema e a literatura de uma forma geral. Assim sendo, alguns aspectos nos serão fundamentais para esta análise, quais sejam: em primeiro lugar, poderíamos pensar que montagem é esta que nos coloca a relação de eles eram muitos cavalos, de Luiz Ruffato (2001) com o cinema, assim como quais as características da obra citada que atuam fazendo com que a mesma recorra a tal artifício, e, por fim, como pode ser pensado o termo montagem diante das implicações políticas e históricas que eles eram muitos cavalos (2001) nos coloca. O esquema traçado pouco deve ser encarado como tal, mas sim como pontos de maior importância que serão tangenciados ao longo da construção deste argumento independendo da ordem em que foram colocados.

\section{A MONTAGEM EM ELES ERAM MUITOS CAVALOS}

(...) o homem é o animal que vai ao cinema.

Giorgio Agamben

\footnotetext{
${ }^{5}$ BENJAMIN, Walter. Que é o teatro épico? IN: Magia e técnica Arte e Politica. Ensaios sobre literatura e história da cultura. Obras escolhidas I, vol. I. Tradução Sergio Paulo Ruanet Pref Jeanne Marie Gagnebin. São Paulo: Brasiliense, 1994. p. 83. Nas considerações sobre o Teatro de Bertold Brecht, tão caras a nós neste momento, Benjamin afirma: "As formas do teatro épico correspondem às novas técnicas, o cinema e o rádio. Ele está situado no ponto mais alto da técnica. Se o cinema impôs o principio de que o espectador pode entrar a qualquer momento na sala, de que para isso devem ser evitados os antecedentes muito complicados e de que cada parte, além do seu valor para o todo, precisa ter um valor próprio, episódico, esse princípio tornou-se absolutamente necessário para o rádio, cujo público liga e desliga a cada momento, arbitrariamente, seus alto-falantes."
} 
Quando se fala de montagem é impossível não evocar a escola soviética da montagem e seu principal representante já citado aqui, Sergei Eisenstein. O cineasta não só realizou inúmeros filmes como deixou um imenso legado escrito com abordagens teóricas acerca do cinema e da montagem que, por sua vez, possuem grande valor. Iremos passar por essa teorização pela leitura de terceiros - por motivos que serão justificados posteriormente - como a presente em um artigo Modesto Carone (1973). O pensador se propõe justamente a realizar uma leitura que aproxima a montagem cinematográfica da literatura. Ao verificar a relação da montagem com a poesia de George Trakl, temos a constatação de que assim como no cinema eisensteiniano, a poesia do escritor especificado vêm promover essa junção "analógica" de elementos que a princípio não possuem relações entre si para que se possa ter como fruto uma "possibilidade semântica" que não pode ser achado em ambos ${ }^{6}$. Há um ímpeto de se obter através da justaposição um resultado, um produto, uma imagem que surge e, entretanto se diferencia das demais que a compuseram. A respeito de Eisenstein, Carone afirma:

Isso equivale a afirmar que a obra de arte mobiliza representações isoladas de cuja interação nasce a "imagem", o "terceiro termo" ou o "sentido". Nesta operação está "implícita a montagem". As representações isoladas ocorrem para formar uma imagem. E esse resultado é obtido através dos processos de montagem. (CARONE, 1978, p. 191).

Segundo ainda o teórico, a montagem seria o grande achado da arte moderna para dominar a realidade, para "apropriar-se dela na totalidade de suas manifestações" (CARONE, 1973, p.191). Vemos uma proximidade explícita entre tal percurso teórico e o que é visível nas relações analisadas entre Eisenstein e Oswald de Andrade por Susanna Busato Feitosa ${ }^{7}$. A teórica ressalta esse caráter dialético que deve ter o ato de se colocar uma imagem após a outra, gerando, assim, um terceiro. Alertamos que não se trata de necessariamente se imputar uma linearidade à narrativa, ou mesmo de fazer emergir processos esquemáticos de causa e conseqüência onde teríamos, por exemplo, a imagem de um homem com expressão desgastada seguida da tomada de um prato vazio,

\footnotetext{
${ }^{6}$ CARONE, Modesto. Em busca de um conceito de montagem. In: Revista Discurso. $4^{\circ}$ Volume. USP 1973. p. 187-193

${ }^{7}$ FEITOSA, Susanna Busato. Oswald e Eisenstein. In: Aletria no 8. Belo Horizonte: 2001. p. 243-251.
} 
fazendo emergir a idéia de que o último sentiria fome. Este era, sim, um dos procedimentos usados por Eisenstein, mas não o único - o cineasta enumera diversos tipos de montagem, como paralela, atonal etc, que definitivamente não no interessa no momento. Susanna Busato resume de forma sucinta o que se passa:

Os conceitos de "relação" e "organização" estrutural estão, para Eisenstein, ligados à concepção de obra como "organismo", um todo orgânico cujas partes estão em correlação. A organização dos fragmentos nesse todo dá-se por meio de uma idéia de "conflito" entre as partes, de modo que, pelo choque, pelo estranhamento entre os elementos, operacionalizados pela montagem, surge a imagem, o conceito abstrato de nível intelectual, e no pensamento organizador do material operacionalizado por Oswald de Andrade, a ironia e a crítica. (FEITOSA, 2001, p. 250)

Há, inevitavelmente, a idéia de que os meios devem desaparecer para mostrar seus fins. Imagens que restam após outras - essas sim, interessam - destituem as primeiras de importância maior numa relação hierarquizante. Segundo Robert Stam ${ }^{8}$, seriam os teóricos da montagem soviéticos estruturalistas avant la lettre, já que os mesmos não reconheciam no plano cinematográfico um sentido intrínseco: estaria este fadado a se inserir numa estrutura maior conferida pela montagem. Há sempre, seja pela metonímia ou pela metáfora, a necessidade de através da justaposição de planos se remeter a outros objetos, codificações ou sensações no espectador; Eisenstein trabalhava com esses procedimentos e sabia que eles eram chaves tanto para a estética quanto para a ideologia que perpassava suas obras. Andrei Tarkovsky ${ }^{9}$ tachava o método de Eisenstein como asfixiante pois nele nada poderia escapar aos esquematismos propostos em uma arte em que ainda poderia se visualizar inúmeras outras potencialidades a serem trabalhadas. Tal característica presente no modo eisenteiniano apontado por Tarkovsky de se construir o filme, seria em decorrência talvez da necessária existência de algo que sempre deveria existir por trás das imagens, alguma coisa que estaria pronta para ser desvendada pelo espectador ou mesmo relatada mais explicitamente no filme. É interessante aqui, a relação que Robert Stam faz entre a montagem de Eisenstein e a publicidade, que nos será mais cara posteriormente, dizendo:

\footnotetext{
${ }^{8}$ STAM, Robert. Introdução à teoria do cinema. Tradução Fernando Mascarello. 2003. Campinas, SP: Papirus Editora.

9 TARKOVSKI, Andrei. Esculpir o Tempo. Tradução Jefferson Luiz Camargo e Luís Carlos Borges. São Paulo: Editora Martins Fontes, 2002.
} 
Além disso, quando destituída de sua base dialética, a montagem "associacionista" eisensteiniana pode ser facilmente transformada nos ideogramas comodificados da publicidade, nos quais o todo é mais que a soma das partes: Catherine Deneuve mais Chanel $\mathrm{n}^{\circ} 5$ é sinônimo de charme, glamour e apelo erótico. (STAM, 2003, p. 58)

Opera de maneira similar ao que temos no cinema, ou seja, através das justaposições de passagens, de momentos que equivaleriam aos planos cinematográficos, o modelo de narrativa encontrado em eles eram muitos cavalos, de Luiz Ruffato (2001). Dediquemo-nos agora a exemplificar a obra literária com alguns trechos assim como realizar uma análise de tais fragmentos. Na passagem de número 47, temos o texto intitulado crânio, onde lemos:

\begin{abstract}
47.0 crânio
lá da comunidade o crânio é o sujeito mais que esquisito mas por isso mesmo o mais querido ele tem dezesseis anos quase um metro e setenta e cinco uns [oitenta quilos É preto que nem a água preta que escorre no meio dos barracos Os dentes brancos e bons como os de ninguém E principalmente ele é meu irmão Embora eu seja moreno puxado pro mulato baixo e faltando
\end{abstract} [dentes

Pouco após a passagem citada, temos o fragmento de número 49, que diz:

\section{Ritual para a terça-feira, Lua em Câncer}

Num canto da sala, arme um pequeno alta, usando flores que tiver em casa. No centro, coloque um pratinho com sementes e ervas e componha com um cristal roda. Acenda uma vela cor-de-rosa e incensos de rosas. Arrume um paninho virgem da cor de sua preferência, abra-o sobre o altar e vá colocando sobre ele as ervas e as sementes. (RUFFATO, 2001, p. 105)

É visível em uma primeira análise a absoluta falta de relação entre as duas passagens. Obviamente que elas irão compor por estarem no mesmo local de enunciação $^{10}$, uma espécie de panorama onde claramente estarão sendo colocadas em

10 FOUCAULT. Michael. A Arqueologia do Saber. Tradução Luiz Felipe Baeta Neves. Petrópolis: Vozes, Lisboa. 1972. Ao analisar os conceitos de enunciado e local de enunciação, 
conexão, mas não há uma relação mais imediata, algo desejado ou pré-estabelecido que poderia emergir da friç̧ão entre os dois enunciados. No primeiro, temos uma narrativa realizada por uma personagem no intuito de descrever outra: ambos moram em uma favela, em meio ao lixo, como é possível se notar na fala que relaciona a negritude de crânio à água podre que circula entre os sobrados. É possível, todavia, discernir aqui uma representação dotada de um referente, ou seja, uma personagem construída para se narrar a respeito de outra, mas que, acima de tudo, ambos poderiam representar vidas no mundo empírico. Pouco após este fragmento a leitura da obra se depara com outra passagem na qual é possível acusar clara semelhança com os textos destituídos de qualquer valor que se encontra em jornais diários, revistas etc: uma espécie de horóscopo ou oferenda supersticiosa, que nos remete a um processo de pastiche.

Apesar de não ser nosso principal enfoque para o momento, mas que não deixa de ser importante para a conclusão deste artigo, percebemos a presença dos simulacros em meio à descrição das vidas que perambulam entres os barracões, debaixo das marquises da cidade como a demonstração - a partir de um procedimento que explicita o livro como meio onde esses enunciados se inscrevem - da impossibilidade de narrar. Existe um autor que se coloca como gesto ${ }^{11}$, se ausentando no momento em que deixa estes outros textos interromperem a narrativa. As personagens se encontram igualmente em um estado inerte onde suas ações e falas são perpassadas por outras vozes. Na passagem intitulada Fran temos esta situação claramente:

(...) outros tempos esteve ligada à rede Globo, papéis secundários em novelas, pontas em especiais, aparições rápidas em programas dominicais, vilã, ingênua. Chegou a, na rua, ser apontada, cutucada, mexida, apalpada, você não é da televisão? Televisão...televisão é pra poucos, pra uns. Nunca sorteada nas graças do diretor certo, do ator certo, do produtor certo, do empresário certo. Paciência. Nada de

o autor afirma: “(...) a materialidade do enunciado não é definida pelo espaço ocupado ou pela data da formulação, mas por um status de coisa ou de objeto, jamais definitivo, mas modificável, relativo e sempre suscetível de ser novamente posto em questão (...) O regime de materialidade a que obedecem necessariamente os enunciados é, pois, mais da ordem da instituição do que da localização espaço-temporal: define ante possibilidades de reescrito e de transcrição (mas também limiares e limites) do que individualidades limitadas e perecíveis." (FOUCAULT, 2007. P. 116)

${ }^{11}$ AGAMBEN, Giorgio. Profanações. Tradução Selvino José Assmann. São Paulo: Boitempo, 2007. p. 63 O autor afirma: “(...) assim como o autor deve continuar inexpresso na obra e, no entanto, precisamente desse modo testemunha a própria presença irredutível, também a subjetividade se mostra e resiste com mais força no ponto em que os dispositivos a capturam e põe em jogo.” 
apelação. Teatro, só peças sérias. Não apareceu nenhuma? Paciência. Cinema, é aguardar. Mas, longe de filme pornô, erótico. Convite para revistas masculinas, aceita estudar. Fotos artísticas porém, sem poses ginecológicas. (RUFFATO, 2001, p. 35)

A narrativa é intercalada entre o relato sobre Fran e seu depoimento na primeira pessoa, que por sua vez, é incapaz de se dar por inteiro em função das outras vozes que tomam o corpo da escrita. Assim, não se constrói uma subjetividade da personagem, assim como o autor está longe de querer transformar sua escrita em um canal para a representação de sua interioridade ${ }^{12}$ : trata-se de pura exterioridade, de deixar se falar pela escrita, pela materialidade do signo. Diferentemente do procedimento que destacava Carone, que colocava a montagem como o achado da arte para remontar a realidade - repetindo mais uma vez as palavras do autor: "apropriar-se (a arte) dela (realidade) na totalidade de suas manifestações” (CARONE, 1973, p.191) aqui o meio pelo qual se constrói a narrativa assemelha-se - analogia já destacada em uma nota - ao teatro épico de Brecht, onde Benjamin destaca que o palco do teatro já não é mais um local, um suporte "sob a forma de 'tábuas que significam o mundo' (ou seja, como um espaço mágico)"13. A capacidade de narrar e de representar é ignorada fazendo com que estes flashes passem a ter valor por si mesmos. Entre diversos outros procedimentos, temos em eles eram muitos cavalos (2001) o inventário: relato de inúmeros objetos que tem importância constituída de certa autonomia, assim como a descrição de passagens da vida cotidiana sem qualquer valor aparente. À semelhança da leitura deleuziana do cinema, é perceptível nos fragmentos de eles eram muitos cavalos (2001) situações óticas-sonoras puras. Obviamente que se trata aqui da análise de um objeto literário, mas a analogia é pertinente pois ressalta algo em comum, que independe do suporte: a valoração do meio ${ }^{14}$ onde se inscreve o discurso independente da finalidade; meio sem fim. Focaremos na montagem e voltaremos nesta característica posteriormente.

12 FOUCAULT. Michael. O Pensamento do Exterior. IN: Ditos e Escritos III. Estética: Literatura e Pintura, Música e Cinema. Organização e seleção de textos: Manoel Barros da Mota. Tradução Inês Autran dourado Barbosa. 2 ed. - Rio de Janeiro: Forense Universitária, 2009.

${ }^{13}$ BENJAMIN, Walter. O que é o teatro épico? IN: Magia e técnica Arte e Política. Ensaios sobre literatura e história da cultura. Obras escolhidas I, vol. I. Tradução Sergio Paulo Ruanet Pref Jeanne Marie Gagnebin. São Paulo: Brasiliense, 1994. p. 79

${ }^{14}$ AGAMBEN, Giorgio. Notes on Gesture. In Means without End. Translated by Vicenzo Binetti and Cesare Casarino. Minneapolis: The University of Minnesota, 2000. P. 58. Agamben afirma: "O gesto é a exibição de uma medialidade: ele é o processo de fazer o meio visível enquanto tal. Trad. livre 
Deleuze descreve acerca do neo-realismo italiano alertando para a fraca relação entre os planos que retira sua capacidade de descrição ao passo que ressalta a imagem enquanto tal, ou como prefere o filósofo: situações óticas-sonoras puras, como já colocado. Para ele, nos filmes de Visconti “os objetos e os meios conquistam uma realidade material autônoma que os faz valerem por si mesmo" (DELEUZE, 1985, p. 13) assim como há nos filmes de Michelangelo Antonioni "uma espantosa exploração dos tempos mortos da banalidade cotidiana (...)espaços vazios, dos quais se diriam terem absorvido personagens e as ações, para deles só conservar a descrição geofísica, o inventário abstrato" (DELEUZE, 1985, p. 14). Eis onde se insere a montagem que é trazida à obra especificada de Luiz Ruffato (2001).

Para Deleuze (1985) montagem já não é mais o ponto principal da obra cinematográfica da forma como pensava Eisenstein, pois ela mesma reside inclusive no interior do plano: no interior desta pequena unidade da película já possível encontrar o artifício da montagem. Isto, pois não interessa exatamente o que resta do embate entre as passagens, mas elas em si mesmas, o que, como ressalta o filósofo, não retira a importância da montagem, mas atribui a ela outro conceito; trata-se aqui de um procedimento que passa a desempenhar outras funções, diferentes daquelas que apontavam os teóricos soviéticos da montagem. Deleuze afirma:

(...) por um lado, o que conta já não é a associação das imagens, a maneira pela qual se associam, mas o interstício entre duas imagens; por outro, o corte numa seqüência de imagens já não é um corte racional que marca o fim de um ou o começo de outra, mas um corte dito irracional que não pertence a uma nem a outra, e começa a valer por si mesmo. (DELEUZE, 1985, p. 240)

Em eles eram muitos cavalos (2001) é possível notar este interstício do qual fala Deleuze, pois trata-se aqui de pequenas frestas por onde essas imagens irão criar suas relações e não no seu sentido como um todo, numa totalidade a qual cada plano corresponde fazendo uma terceira imagem surgir na sua inteireza. Ou seja, trata-se de inúmeras relações, como em uma rede, que podem ser criadas entre os planos - a cor, o som, a fotografia, as formas etc - conectando-as de acordo com uma imensa pluralidade de características. Obviamente que a associação agora passa a ser mais tarefa do espectador, que não fará uma decodificação pré-estabelecida pelo diretor pois, há poucos instrumentos para indicar um caminho específico para a leitura. A obra agora passa a ser uma espécie de labirinto. 
É interessante que Deleuze (1985) veja este corte que intercala duas imagens como um procedimento que faz explicitar o corpo desta mídia - o filme -, revelando este local de enunciação. Agambem coloca muito bem esta situação ao observar que no cinema moderno - o autor se refere a Guy Debord, mas também expande sua análise ao cinema de Godard - este corte, tal qual Deleuze falava, "não se trata mais de um corte no sentido de uma pausa, cronológica, mas antes de uma potência de corte que trabalha a imagem ela mesma, que subtrai ao poder narrativo para expô-la enquanto tal". ${ }^{15}$

O corte é o que compõe a montagem, e da forma como ele é feito no conjunto das obras especificadas que se relacionam com o objeto em pauta, exibe-se o corpo, a materialidade da mídia. O cinema se mostra enquanto tal justamente nesta mudança conceitual pela qual passa a montagem, assim como é perceptível em eles eram muitos cavalos (2001), de Luiz Ruffato. Deleuze investiga acerca desta montagem, relatando justamente da passagem do que ele chama de esquema sensórios-motores para situações puramente ótico-auditivas, onde se tem uma imagem-tempo, não mais uma imagemmovimento. Afirma Deleuze:

\begin{abstract}
Mas a montagem mudou de sentido, ganhou nova função: em vez de ter por objeto as imagens movimento, das quais ela retira uma imagem indireta do tempo, tem por objeto a imagem-tempo, extrai dessas as relações de tempo, das quais o movimento aberrante agora apenas depende. Conforme uma expressão de Lapoujade, a montagem tornouse "mostragem" (DELEUZE, 1990, p. 56)
\end{abstract}

A relação da imagem com o tempo passa a ser um dos pontos fundamentais na leitura do cinema promovida por Deleuze. Estaríamos diante, neste conjunto de obras que o filósofo intitula como cinema moderno, de películas que não mais se preocupam em destacar o movimento e enfatizá-lo, como acontecia no cinema clássico, mas que agora se atêm a mostrar o fluir do tempo e seus lençóis ${ }^{16}$ ao alternar diversas dilatações do mesmo - atentaríamos para o tempo da "montagem" ou do campo/contra-campo que é confrontado com o "tempo real" do plano seqüência, com o lento andar das tomadas acerca de trivialidades, que provocam essa dilatação do tempo, ora se retraindo, ora se expandindo. Ainda, com a circularidade que a obra passa a adquirir em função desta

15 AGAMBEN, Giorgio. O Cinema de Guy Debord. Tradução do francês Antonio Carlos Santos. Conferência em Genève, Nov 1995.

${ }^{16}$ DELEUZE, Gilles. A imagem-movimento. Trad. Stella Senra. São Paulo: Brasiliense, 1985. p. $87-141$ 
nova estrutura de organização, ou mesmo da falta de estrutura, a noção de tempo passa a ser levada a outras esferas. Tem-se a valoração do momento em detrimento da estrutura narrativa linear que se proporia a representar um determinado fato na sua suposta inteiridade, assim como o anacronismo se torna recorrente. Acima de tudo, é importante observar que com a valoração do meio em detrimento dos fins, essas imagens, ou fragmentos como temos em eles eram muitos cavalos (2001), passam a ser recheados de potência, pois pouco se dão como algo consumado. Ou seja, a valorização do significante em detrimento do significado deixa essas imagens abertas à significação, o que permite que elas possam retornar: sua potencialidade é valorizada. Tarkovsky nos diz desta condição ao falar sobre o cinema de Eisenstein.

A idéia de "cinema de montagem" — segundo a qual a montagem combina dois conceitos e gera um terceiro - parece-me, mais uma vez, incompatível com a natureza do cinema. A interação de conceitos jamais poderá ser o objetivo fundamental da arte. A imagem está presa ao concreto e ao material, e, no entanto, ela se lança por misteriosos caminhos, rumo a regiões para além do espírito — talvez Puchkin se referisse a isso quando disse que "A poesia tem que ter um quê de estupidez". (TARKOVSKY, 2002, p. 135)

Este quê de estupidez de estúpido não há nada: não seria exatamente o que Valery ${ }^{17}$ diz quando afirma que a "poesia é a hesitação entre o som e o sentido"? Na pequena lacuna que reside na junção dos significantes - quando pensamos na rima, as palavras se juntam mais pelo som que pelo sentido - por determinadas características que ignoram a relação causal entre os significados? Assim, o cinema moderno da mesma maneira que eles eram muitos cavalos (2001) opera a partir deste vazio do significado, que como já foi colocado, fazendo emergir a pluralidade do sentido já que os significantes poderão sempre ser preenchidos de acordo com as inúmeras leituras que eles se deixam realizar. Tarkovsky (2002) tinha consciência deste processo e via a necessidade de trazer a poesia e sua resistência em escapar ao sentido majoritário, à linguagem estanque, ao relato histórico cronológico feito pelas autoridades que colocam o passado como imutável.

O diretor russo separa muito claramente o cinema que era praticado a partir da noção que Eisenstein colocava ao cinema e à montagem e o que vem realizando as vanguardas cinematográficas que se inicia em meados dos anos 50 - é óbvio que este

\footnotetext{
${ }^{17}$ VALERY, Paul. Poesia e Pensamento Abstrato. In variedades. São Paulo: Iluminuras, 1993
} 
tipo de distinção realizada aqui não pretende categorizar toda a produção cinematográfica justamente por saber que há inúmeros diretores que se colocam em pontos intermediários, de indefinição e indistinção: o que é de principal relevância é o fato de poder conseguir identificar dois momentos distintos da produção cinematográfica, que dizem conseqüentemente de duas produções com características diferentes - já que no primeiro, segundo Tarkovsky, nota-se uma espécie de quebra cabeça constituído de inúmeros enigmas onde devem ser decifrados símbolos, alegorias: e todas estas charadas possuem soluções ${ }^{18}$. "Também não tem nada a ver (a montagem) com dois conceitos semelhantes que - segundo nos dizem - produzem, quando combinados, um "terceiro significado", mas sim com a diversidade da vida percebida." (TARKOVSKY, 2002. p. 142) nos diz o diretor.

Em eles eram muitos cavalos (2001) a importância que se dá ao significante nos remete à vida que ganham as palavras e os objetos no cinema moderno lido por Deleuze (1985). A palavra e o texto exibem seu corpo deixando que os fragmentos se liguem pelas conexões realizadas por aquele que lê. Na obra, temos:

alguns segundos? minutos? um par de sapatos um par de tênis solas gastas aproximam-se bitucas folhas copos descartáveis pombos guardanapos palitos papéis de bala poça de mijo (RUFFATO, 2001, p. 59)

Neste processo de justaposição, o livro opera de uma maneira onde não se faz necessário que se comece a ler do princípio ou do meio. No fragmento colocado é perceptível este inventário, e como destacava Deleuze (1985) os objetos ganham vida: passa a ser puro meio. São folhas, copos, pombos e guardanapos: são, antes, palavras. E o que nos dizem palavras que apenas comunicam sua condição de palavras? Em eles eram muitos cavalos (2001) a explicitação do meio através de todos esses processos relatados, da montagem a qual estamos delineando as características, dizem de um importante aspecto: impossibilidade. Trazer a metrópole contemporânea em sua totalidade, trazer o mundo tal qual ele é, remontar a interioridade do autor, e principalmente: representar a catástrofe urbana, a vida nua ${ }^{19}$ que perambula em meio ao

\footnotetext{
${ }^{18}$ TARKOVSKI, Andrei. Esculpir o Tempo. Trad. Jefferson Luíz Camargo. São Paulo: Editora Martins Fontes, 2002. p. 140.

${ }^{19}$ AGAMBEN, Giorgio. Homo Sacer. Poder Soberano e Vida Nua I, tradução Henrique Burigo. Belo Horizonte: Editora UFMG, 2002. Giorgio Agamben define a vida nua como o corpo biológico destituído de qualquer intervenção política.
} 
lixo urbano, às favelas. Há em eles eram muitos cavalos (2001) a constatação da insuficiência da linguagem de se retratar o absurdo, a catástrofe. Nota-se que o cinema ao qual Deleuze dedica sua análise se desenvolve justamente após o fim da segunda guerra mundial, onde a humanidade viveu a experiência do fascismo e Auschwitz - um dos maiores campos de extermínio construído pelo nazismo alemão na polônia. Hiroshima Mon Amour (1959), de Alan Resnais, que profana sobre a experiência indizível de Hiroshima, ao começo do filme nos remonta justamente esta impossibilidade: retratar o horror, a catástrofe. Diz Deleuze:

\begin{abstract}
Mas, justamente, o que põe em questão esse cinema de ação pósguerra é a própria ruptura do esquema sensório-motor: a ascensão de situações as quais já não podemos reagir, de meios com os quais só temos relações aleatórias, de espaços quaisquer vazios ou desconectados que substituem as extensões qualificadas. De repente as situações já não se prolongam em ação ou reação, como exigia a imagem-movimento. São puras situações óticas e sonoras, nas quais a personagem não sabe como responder, espaços desativados nos quais ela deixa de sentir e agir, para partir para a fuga, a perambulação, o vaivém, vagamente indiferente ao que lhe acontece, indecisa sobre o que é preciso fazer (DELEUZE, 1985, p. 322)
\end{abstract}

Há como diz Deleuze, uma nulidade radical na informação dada pelo jornal, pela mídia, pois ela ao passo que se diz trazer o fato em sua totalidade o isola e o coloca como dado consumado. Assim, o fascismo, os campos de concentrações e Hitler ficam no relato histórico como fatos isolados, destituídos de potência. Ora, essa potencialidade reside justamente no momento da tomada de consciência sobre a impossibilidade de se relatar Auschwitz, pois assim se manterá os olhos fixos no inenarrável ${ }^{20}$ e na tentativa de profaná-lo, pois sabe-se que justamente pelo seu caráter fugidio - entende-se o real (e a vivência do absurdo deixa isso mais explícito) como esse elemento que está em constante fuga sendo perseguido pela linguagem que nunca o alcançará - é que ele pode retornar e se colocar no meio de nós. Como diz Agamben, ao expor a necessidade de se falar sobre o horror dos campos de concentração: "Nós, pelo contrário, "não nos envergonhamos de manter fixos os olhos no inenarrável'. Mesmo ao preço de descobrirmos que aquilo que o mal sabe de si, encontramo-lo facilmente em nós" (AGAMBEN, 2008, p.42).

\footnotetext{
${ }^{20}$ AGAMBEN, Giorgio. O que Resta de Auschwitz. O Arquivo e a Testemunha. Homo Sacer III. Tradução Selvino José Assmann. São Paulo Boitempo, 2008.
} 
É onde se situa eles eram muitos cavalos (2001): neste conjunto de obras que exprimem o inexpressável através de sua própria inexpressabilidade. Arthur Nestrovski (2004) coloca de modo bem claro esta situação ao analisar o documentário Shoah (1985), no qual temos entrevistas com pessoas que viveram no campos de concentração.

Diz o autor:

Pode-se falar em "proibição das imagens", mas fazendo um elo com o que vimos antes sobre a noção do sublime e da inexpressabilidade, talvez seja melhor descrever a ausência de representação, aqui, como outro tipo paradoxal de representação - que é a representação do que não se pode representar, a representação da irrepresentabilidade. (NESTROVSKI, 2004, p. 155)

Mas talvez, a diferença da especificada obra Luiz Ruffato seja justamente aquilo que foi colocado por Agamben (2008) acima: reside a importância de se colocar a incapacidade de se falar, de se remontar a experiência do horror ao passo que a tentativa, a profanação desta experiência também se coloca. Ou seja, em eles eram muitos cavalos (2001) nós temos, neste processo de montagem, a narrativa que traz o abjeto, a vida como lixo, perpassada pelo simulacro que a silencia. Trata-se dos horóscopos, pedaços de jornais e outros artifícios já exemplificados, que intercalam a voz do autor calando-a, fazendo emergir esta narrativa impossível: quem nem só pela sua impossibilidade deixa de existir. Temos na obra:

"Um rato, de pé sobre as patinhas traseiras, rilha uma casquinha de pão, observando os companheiros que se espalham nervosos por sobre a imundície, como personagens de um vídeo-game. Outro, mais ousado, experimenta mastigar um pedaço de pano emplastrado de cocô mole, ainda fresco, e, desazado, arranha algo macio e quente, que imediatamente se mexe, assustando-o.

O corpinho débil, mumificado em trapos fétidos, denuncia o incômodo, o músculo da perna se contrai, o pulmão arma-se para o berreiro, expele um choramingo entretanto, um balbucio de lábios magoados, um breve espasmo. (...) Mas, é noturno ainda o barraco. (RUFFATO, 2001, p. 19)

Ao passo que estas narrações - o trecho acima se refere a uma criança que vive nesse estado de imundície; no início, o narrador relata sobre os ratos que invadem o sobrado no qual se encontra a criança, o que resulta em interessante efeito, enganando o leitor fazendo-o pensar que a narrativa presente no segundo parágrafo dedicada às 
crianças era destinada aos ratos - trazem a representação desta vida sem valor, deste corpo como abjeto, do lixo e da catástrofe contemporânea, o livro as interrompe através de um corte em que a próxima imagem é um simulacro. Processo similar ao realizado por Guy Debord, que realizou o filme $A$ Sociedade do Espetáculo (1973) usando apenas imagens de outros filmes: as imagens são a própria catástrofe. Temos em eles eram muitos cavalos:

\author{
36. Leia o Salmo 38 \\ Leia o salmo 38 \\ Durante três dias seguidos \\ Três vezes ao dia \\ Faça dois pedidos difíceis \\ E um impossível \\ Anuncie no terceiro dia \\ Observe o que acontecerá no quarto dia (RUFFATO, 2001, p. 3)
}

Por fim, algumas perguntas não querem calar. Basta um procedimento metalingüístico para que se tenha todo este panorama narrado? Somente ele é capaz de dar a essas imagens a potência que elas não teriam? E ainda, o que faria com que esta montagem que estamos discutindo fosse a buscada pelos diretores do cinema pósguerra? Porque é justamente esta montagem que se faz presente em Luis Ruffato? Para começar o esboço para uma possível resposta a estas perguntas, destaquemos um ponto: há uma relação entre as imagens e a história muito bem analisada por Agamben (2007) que podem ser um ponto chave para a discussão.

Agamben (2007) retoma questões levantadas antes por Benjamin (1936). Tratase no último pensador, de trabalhar aspectos relativos ao judaísmo, fazendo uma mistura entre teologia e materialismo histórico. Benjamin ${ }^{21}$, no terceiro fragmento das teses sobre o conceito de história, afirma que somente no momento em que a humanidade puder falar sobre cada instante de seu passado, quando qualquer fato vivido puder vir à tona e se tornar citável é que ela alcançará a redenção. E este dia, segundo o teórico alemão, será justamente o dia do juízo final. Mas como mostra Michael Löwy ${ }^{22}$, o dia do juízo final na teologia judaica pode significar também o dia da redenção, o dia da

\footnotetext{
${ }^{21}$ BENJAMIN, Walter. Tese sobre o conceito da História. In Magia e técnica Arte e Política. Ensaios sobre literatura e história da cultura. Obras escolhidas I, vol. I. Tradução Sergio Paulo Ruanet Pref Jeanne Marie Gagnebin. São Paulo: Brasiliense, 1994.

${ }^{22}$ LÖWY, Michael. Walter Benjamin: aviso de incêndio. Uma Leitura das Teses "Sobre o Conceito de História”. Tradução Wanda Nogueira Caldeira Brant. São Paulo: Boitempo, 2005.
} 
chegada do messias. Agamben (2007) se dedica justamente a esse ponto, nos dizendo recorrendo à teologia judaica - que há cálculos proibidos para descobrirem a chegada do messias, mas cálculos que são impossíveis, pois a chegada do messias é incalculável ${ }^{23}$. Assim, cada momento seria o momento de sua chegada, "cada imagem é carregada de história, porque ela é a pequena porta pela qual entra o messias" (AGAMBEN, 2007, p. 2). Agamben completa:

Compreendemos então porque um trabalho com as imagens pode ter uma tal importância histórica e messiânica, porque é uma maneira de projetar a potência e possibilidade na direção do que é impossível por definição, em direção ao passado. $\mathrm{O}$ cinema faz, portanto, o contrário do que fazem as mídias. Os meios de comunicação nos dão sempre um fato, o que aconteceu, sem sua possibilidade, sem sua potência (...) (AGAMBEN, 2007.p. 4)

Ao início do artigo, fizemos questão de ler Eisenstein por meio de terceiros - o que não significa que seus livros não tenham sido lidos para este trabalho-, justamente para trazê-lo junto com a literatura com a qual sua obra se relacionava. Eis aqui, o cinema com o qual eles eram muitos cavalos (2001) se relaciona, pois está nessa montagem a imagem como potência: Auschwitz não como fato isolado tal qual trazem os meios de comunicação de massa, mas como possibilidade sempre na eminência de seu retorno e lembrando-nos o ponto inaceitável ao qual a sociedade um dia chegou e dizendo-nos ainda que não estamos tão longe dele assim. Como Benjamin ressalta, é preciso trazer os restos da história, aquilo tudo que está de fora do relato totalizante e cronológico daqueles que venceram através da barbárie: eis o que temos em Ruffato, o abjeto, o lixo cultural, o instante trivial, palavras sem referentes, as vidas marginais, o silêncio, entre outros.

Havíamos nos indagado sobre a metalinguagem. Robert Stam (2008), como indicado ao início deste texto, relacionava a montagem eisensteiniana com a publicidade. Há uma pertinência nisso. Agambem (2007) nos diz da importância da imagem que se mostra como meio puro, que não desaparece naquilo que nos dar a ver, permanecendo, assim, como potência ao preservar sua possibilidade de existência, de volta e repetição - como o relatado acima. Mas há duas situações. Agamben nos relembra o filme Monika (1953) de Ingmar Bergman onde, pela primeira vez a

${ }^{23}$ AGANBEM, Giorgio. O Cinema de Guy Debord. Tradução do francês Antonio Carlos Santos. Conferência em Genève, Nov 1995. 
personagem olha para a câmera; o teórico nos diz: "desde então, a pornografia e a publicidade vem banalizando tal procedimento" (AGAMBEN, 2007, p. 6). Desta forma, o teórico faz uma separação: para ele, há duas formas de uma imagem se mostrar enquanto tal. Diz Agamben:

Há duas maneiras de se mostrar essa relação com o "sem-imagem", duas maneiras de dar a ver que não há mais nada a ver. Uma, a pornografia e a publicidade que fazem como se houvesse algo a ver aí, sempre imagens por trás das imagens: outra que, nessa imagem exposta enquanto imagem, deixa aparecer esse "sem-imagem" que é, como dizia Benjamin, o refúgio de toda imagem. É nessa diferença que se joga toda a ética e toda política do cinema. (AGAMBEN, 1995, p. 7)

Então é necessário retomar o que havia sido colocado ao começo deste artigo: não se trata de necessariamente de o filme simplesmente suspender a cronologia, ou mostrar seu local de enunciação. Na montagem eisenteiniana, residia sempre algo a ver, sempre uma imagem por de trás das outras: o que Robert Stam já detectava banalizado pela publicidade. O livro eles eram muitos cavalos (2001) possui as páginas 147 e 148 completamente negras: não há nada a ver por de trás. A própria literatura abdica neste momento do seu instrumento maior, a escrita, e recorre às telas e negras de Debord: eis aí esse sem-imagem. 


\section{REFERÊNCIAS}

ANDRADE, Oswald. Memórias sentimentais de João Miramar. Rio de Janeiro: Editora Civilização Brasileira. 1973

AGAMBEN, Giorgio. Notes on Gesture. In Means without End. Translated by Vicenzo Binetti and Cesare Casarino. Minneapolis: The University of Minnesota, 2000.

São Paulo: Boitempo, 2004

Estado de Exceção. Homo Sacer, II, 1. Tradução Iraci D. Poleti. - Profanações. Tradução Selvino José Assmann. São Paulo:

Boitempo, 2007.

. O Cinema de Guy Debord. Tradução do francês Antonio Carlos Santos. Conferência em Genève, Nov 1995.

. O que resta de Auschwitz. O Arquivo e a Testemunha. Homo Sacer III. Tradução Selvino José Assmann. São Paulo Boitempo, 2008.

Homo sacer. Poder Soberano e Vida Nua I, tradução Henrique

Burigo. Belo Horizonte: Editora UFMG, 2002.

BAUDRILLARD, Jean. Simulacra and simulation. Translated by Sheila Faria Glaser. The University of Michigan, 1994

BENJAMIN, Walter. A obra de arte na era da reprodutibilidade técnica. In Magia e técnica Arte e Politica. Ensaios sobre literatura e história da cultura. Obras escolhidas I, vol. I. Tradução Sergio Paulo Ruanet Pref Jeanne Marie Gagnebin. São Paulo: Brasiliense, 1994.

- Tese sobre o conceito da história. In Magia e técnica arte e política. Ensaios sobre literatura e história da cultura. Obras escolhidas I, vol. I. Tradução Sergio Paulo Ruanet Pref Jeanne Marie Gagnebin. São Paulo: Brasiliense, 1994.

O que é o teatro épico? IN: Magia e técnica Arte e Política. Ensaios sobre literatura e história da cultura. Obras escolhidas I, vol. I. Tradução Sergio Paulo Ruanet Pref Jeanne Marie Gagnebin. São Paulo: Brasiliense, 1994.

CARONE, Modesto. Em busca de um conceito de montagem. In: Revista Discurso. $4^{\mathrm{o}}$ Volume. USP 1973. p. 187-193 
COMPAGNON, Antoine. O Trabalho da citação. Tradução Cleonice P.B. Mourão. Belo Horizonte: Editora UFMG, 2007

DELEUZE, Gilles. A imagem-tempo. Tradução Stella Senra. São Paulo: Brasiliense, 1985.

. Mil platôs: capitalismo e esquizofrenia V. 1. Tradução Ana Lúcia de Oliveira. São Paulo: Editora 34. $5^{\circ}$ reimpressão, 2007

EISENSTEIN, Sergei. A forma do filme. Tradução Teresa Ottoni. Rio de Janeiro: Editora Zahar, 2002

FEITOSA, Susanna Busato. Oswald e Eisenstein. In: Aletria $\mathrm{n}^{\mathrm{o}}$ 8. Belo Horizonte: 2001. p. 243-251.

FOUCAULT. Michael. A Arqueologia do saber. Tradução Luiz Felipe Baeta Neves. Petrópolis: Vozes, Lisboa. 1972

.O Pensamento do exterior. IN: Ditos e Escritos III. Estética: Literatura e Pintura, Música e Cinema. Organização e seleção de textos: Manoel Barros da Mota. Tradução Inês Autran dourado Barbosa. 2 ed. - Rio de Janeiro: Forense Universitária, 2009.

.O que é um autor? IN: Ditos e Escritos III. Estética: Literatura e Pintura, Música e Cinema. Organização e seleção de textos: Manoel Barros da Mota. Tradução Inês Autran dourado Barbosa. 2 ed. - Rio de Janeiro: Forense Universitária, 2009.

LÖWY, Michael. Walter Benjamin: aviso de incêndio. Uma Leitura das Teses "Sobre o Conceito de História”. Tradução Wanda Nogueira Caldeira Brant. São Paulo: Boitempo, 2005.

NESTROVSKY, Arthur. Shoah: catástrofe e representação. IN: Textos à flor da tela SEDLMAYER, S.;MACIEL, M.E. (Org.) p. 145-168 Belo Horizonte: FALE/UFMG, 2004

RUFFATO, Luiz. Eles eram muitos cavalos. Boitempo Editorial, 2001

STAM, Robert. Introdução à teoria do cinema. Tradução Fernando Mascarello. Campinas, SP: Papirus Editora. 2003

TARKOVSKI, Andrei. Esculpir o tempo. Tradução Jefferson Luiz Camargo e Luís Carlos Borges. São Paulo: Editora Martins Fontes, 2002.

VALERY, Paul. Poesia e pensamento abstrato. In variedades. São Paulo: Iluminuras, 1993 
FILMOGRAFIA

BERGMAN, Ingmar. MONIKA. Produção: Suécia, 1953, p\&b, 92 min.

DEBORD, Guy. A SOCIEDADE DO ESPETÁCULO. Produção: França, 1973, p\&b, $88 \mathrm{~min}$.

LANZMANN, Claude. SHOAH. Produção: França, 1985.566 min

RESNAIS, Alan. HIROSHIMA MON AMOUR. Produção: França/ Japão, 1956, p\&b, 86 min. 